\title{
Rechtsgeschichte
}

http://www.rg-rechtsgeschichte.de/rg1

Zitiervorschlag: Rechtsgeschichte Rg 1 (2002)

$\operatorname{Rg} 2002$

$261-262$

http://dx.doi.org/10.12946/rg01/261-262

\section{Karl-Heinz Lingens}

\section{Dreiste Wahrheiten?}

Rechtsunterricht für einen Thronfolger 


\section{Dreiste Wahrheiten?}

Rechtsunterricht für einen Thronfolger*

Friedrich der Große war misstrauisch: Viel sei gewonnen, wenn man einem künftigen Herrscher Geschmack an Lektüre vermittele, da man nie so gut von Lehrern lerne wie durch sich selbst. Zudem habe die Unterhaltung mit den Toten, die man nicht beschuldigen könne, eigennützig zu sein, mehr Kraft als die mit den Lebenden. Liege es doch im Interesse der einflussreichen Minister und Geistlichen, den Prinzen in Furcht und Abhängigkeit zu halten; die guten Absichten seiner Eltern würden ihn dann vollends verderben.

Gleichwohl kam wenig später der junge Friedrich Wilhelm (III.) in den Genuß von Privatlehrern. Schon sein Großonkel, eben jener Friedrich, bestellte ihm Lehrer in Philosophie. Und sein Vater, Friedrich Wilhelm II., sorgte anschließend für die weitere Ausbildung. Er berief Ende I790 keinen Geringeren als Carl Gottlieb Svarez, um dem Thronfolger die Grundsätze des Allgemeinen Staatsrechts beizubringen. Dieser Auftrag wurde im Sommer I79I auf die Vermittlung des Völkerrechts, des deutschen Staats- und Fürstenrecht sowie des positiven preußischen Rechts erweitert und Ende März 1792 nach fast einhundert Vorlesungsstunden (so die Schätzung Krauses) beendet.

Dieses faszinierende Kompendium juristischen Grundwissens aus der Zeit der Französischen Revolution ist nun erstmals in vollständiger Form zugänglich. Vollständig heißt: Die Edition enthält sowohl die Vorlesungsmanuskripte als auch die Friedrich Wilhelm am Ende jedes Themas überreichten schriftlichen Zusammenfassungen. Der Herausgeber Peter Krause ist nach eingehender Prüfung der Materialien über- zeugt, dass es entgegen der bisherigen - auf die erste zeitgenössische Sichtung im Auftrag des preußischen Justizministers zurückgehende Ansicht - auch keine Lücken in der Überlieferung gibt. In seiner längeren Einleitung, die zu Überlieferungsgeschichte, Reihenfolge, Umständen und Entstehungsbedingungen der Vorlesungen Stellung nimmt, betont der Herausgeber zu Recht, dass die Kronprinzenvorträge nicht nur für das Recht und die Rechtslehre jener Zeit bedeutsam sind, sondern auch im Hinblick auf den Auftraggeber, die Auswahl der Lehrer und die Person des Adressaten.

Bisher ging es der Forschung vor allem darum, aus den Svarezschen Ausführungen die "geschlossene Gedankenwelt des Allgemeinen Gesetzbuchs « (Conrad in der Einleitung zur Edition von I960) herauszuarbeiten, um den Einfluss der Aufklärung auf die Reformgesetzgebung in Preußen zu dokumentieren. Aber die Vorträge sind nicht nur eine hervorragende Interpretationshilfe für rechtliche Prozesse, sie haben auch als besondere Quellengattung einen eigenen, wissenschaftsgeschichtlichen Wert. Die Überlegungen Friedrichs des Großen in seinen zu Lebzeiten geheimgehaltenen Testaments Politiques von 1752 und 1768 zeigen ja, dass er juristische Vorträge zur Erziehung des künftigen Herrschers weder in der Form noch in der Sache in Betracht gezogen hatte. Warum sie relativ bald nach seinem Tod einen zentralen Platz in der Ausbildung des Thronfolgers erhielten, dieser Frage nachzugehen lohnt trotz der offenbar schlechten Quellenlage weitere Forschungsanstrengungen. War es das Wiener Vorbild? Dort wurde schon Ende der I75oer Jahre der nach-

\footnotetext{
* Carl Gottlieb Svarez, Kronprinzenvorlesungen, (Gesammelte Schriften, hg. von Peter Krause in Verbindung mit der Forschungsstelle Vernunftrecht und Preußische Rechtsreform der Universität Trier. Erste Abteilung: Eigene Werke. Bd. 4), 2 Bde, StuttgartBad Cannstatt: frommann-holzboog $2000, \mathrm{XC}, 948 \mathrm{~S}$., ISBN 3-7728-I 793-9
} 
malige Kaiser Joseph II. von Christian August Beck in den juristischen Fächern unterrichtet, während andere Erzherzöge und Erzherzoginnen etwas später Karl Anton von Martini als Lehrer erhielten. Oder hatte die Rechtswissenschaft an Ansehen und Einfluss gewonnen? Für deren Vertreter bot der Unterricht des fürstlichen Nachwuchses eine einmalige Chance, denn nicht nur im Allgemeinen Staatsrecht (so Svarez), sondern auch im Natur- und Völkerrecht galten die Herrscher seit dieser Zeit als wichtigste »Zielgruppe«: "Le Droit des Gens est la Loi des Souverains. C'est pour eux principalement, \& pour leur Ministres, qu'on doit l'écrire." (Vattel I758). Neue Strömungen, etwa das von J.J. Moser propagierte »Völcker-Recht, wie es unter den Europäischen Souverainen und Nationen üblich ist «, suchten sich durch ihre Nützlichkeit für den selbstbewussten Herrscher zu legitimieren und kamen damit den Vorstellungen Friedrichs entgegen, der selbständiges Handeln und Stärkung der Urteilskraft als Erziehungsziele für künftige Regenten propagierte.

Nicht verkannt werden darf allerdings, dass die neue Aufgabe auch mit unangenehmen Zwängen verbunden war. So versuchte etwa der Vizekanzler Johann Christoph von Bartenstein besagtem Rechtslehrer Christian August

\section{Geistergeschichte*}

Martin Kühnels politikwissenschaftliche Dissertation verfolgt zielstrebig ein klares Programm: Sie nähert sich dem politischen Denken von Christian Thomasius systematisch. Kühnel analysiert die wesentlichen Aspekte der politischen, juristischen und philosophischen Ideen-
Beck Materialien aufzudrängen und dadurch den Inhalt von dessen Vorlesungen zu beeinflussen. Eben solche Interventionen durch höfische Interessengruppen hatte Friedrich der Große befürchtet. Zudem war gerade im Allgemeinen Staatsrecht die Gefahr groß, dass Opportunismus in welcher Form auch immer die Lehrinhalte bestimmte. Nicht umsonst glaubte Svarez sich in seinem Schlussvortrag für "dreiste Wahrheiten ..., welche den Ohren der Fürsten selten willkommen sind «, entschuldigen zu sollen.

Die Verortung der Kronprinzenvorträge in diesem Spannungsfeld machen sie im Einzelfall wie als Gattung interessant. Sicher müssen sie, wie in den beim Herausgeber entstandenen Dissertationen von Thomas Karst (Das Allgemeine Staatsrecht im Rahmen der Kronprinzenvorträge, Hamburg 2000) und Robert Schelp (Das Allgemeine Staatsrecht - Staatsrecht der Aufklärung, Berlin 200I), auch als Teil der Geschichte der jeweiligen juristischen Disziplin verstanden werden. Gleichzeitig bieten sie aber die Gelegenheit, den Stellenwert von Recht und Rechtswissenschaft in Staat und Gesellschaft zu erforschen. Sorgfältige Editionen wie die vorliegende sind dafür hoch willkommen.

Karl-Heinz Lingens

welt des deutschen Frühaufklärers. Das ist überwiegend gelungen, weist aber einige Schwächen auf, die in erster Linie durch die Anlage der Arbeit bedingt sind und die beim Leser letztlich die Frage nach dem prinzipiellen Wert solcher Rekonstruktionen aufkommen lassen.

\footnotetext{
* Martin Kühnel, Das politische Denken von Christian Thomasius. Staat, Gesellschaft, Bürger, Berlin: Duncker \& Humblot 200I, 404 S., ISBN 3-428-10260-6
} 